\title{
Bridging Ugandan Graphic Design Courses Closer to Chinese and Western Education Standards
}

\author{
Nsiima Juliet Kategaya \\ School of Art and Design, Wuhan University of Technology, Wuhan, China \\ Email: jnsiima@gmail.com
}

How to cite this paper: Kategaya, N. J. (2018). Bridging Ugandan Graphic Design Courses Closer to Chinese and Western Education Standards. Creative Education, 9, 1931-1944.

https://doi.org/10.4236/ce.2018.913141

Received: July 16, 2018

Accepted: October 15, 2018

Published: October 18, 2018

Copyright $\odot 2018$ by author and Scientific Research Publishing Inc. This work is licensed under the Creative Commons Attribution International License (CC BY 4.0).

http://creativecommons.org/licenses/by/4.0/

\section{(c) (i) Open Access}

\begin{abstract}
Graphic design education in the West and China is at a more modern and specialised level than Uganda. This situation ensures that Western and Chinese graphic design students get better employment and job security compared to Ugandan design students. Ugandan education systems need to invest in early-age studies in order to create better chances for future graphic design students to get employment and become investors in this field. This paper discusses comparisons amongst Western, Chinese and Ugandan education systems and give suggestions on how to bridge the gaps. It concludes by suggesting how direct and indirect changes may advance the future job opportunities of graphic design students in Uganda with examples from China and the West.
\end{abstract}

\section{Keywords}

Uganda, China, the West, Graphic Design, Early-Age Studies

\section{Introduction}

Graphic design today is an integral part of visual communication, research studies, manufacturing, marketing and commerce. The American designer called William Addison Dwiggins (1880-1956) is the man that proposed the word "graphic design" to encompass the term "printing pre-work". During his time, graphic design was used for large volume printing that generally meant to prepare a print design and get it ready for large volume printing (Yang \& Sun, 2016).

Print, film and web graphic designs influence the branding, advertising and marketing sectors today. In the West (Europe and North America) and China, 
graphic designers survive and prosper from their work and do not have to do additional work such as painting, calligraphy, distribution of art/design products, like in the past, or like in today's Uganda. Graphic design study courses come in various packages and for various purposes. But they can be summarised into three categories-image processing software, graphics software and Workgroup Edition software (Luo, 2011). There are several categories of graphic design course that are currently taught in Uganda, China and the West today. They are shown in Table 1.

\section{Research Method}

This will be a qualitative research study whereby I will use published studies of graphic design theory in the West (Europe and North America) and China to highlight the gaps in the current Ugandan education and employment systems. I will highlight social and historic factors in the West, China and Uganda's past to explain why there are positive and negative situations in various education systems today. Finally being a woman graphic designer for almost two decades, I will give personal observations and my workmates observations of our employment experiences.

Table 1. Categories of graphic design studies in Uganda, China and the western world today.

\begin{tabular}{|c|c|c|}
\hline \multirow{2}{*}{ No. } & \multicolumn{2}{|c|}{ Graphic Design Study Courses } \\
\hline & Category & Content/Output \\
\hline 1. & Identification system design & $\begin{array}{l}\text { (i) Corporate identification system-logo, standard } \\
\text { text, standard color, business card, envelope, letter } \\
\text { paper. } \\
\text { (ii) Environment identification } \\
\text { system-environmental direction, } \\
\text { position and indicators. } \\
\text { (iii) Activity identification system - activity logo, } \\
\text { mascot, event banner. }\end{array}$ \\
\hline 2. & Promotion design & $\begin{array}{l}\text { DM, poster, catalogues, greeting cards, illustrations, } \\
\text { calendars, flyers, brochures. }\end{array}$ \\
\hline 3. & Layout design & Newspapers, magazines, books, journals, yearbooks. \\
\hline 4. & Packaging design & $\begin{array}{l}\text { Packaging boxes, packaging bags, packaging } \\
\text { structures, packaging materials, application } \\
\text { of structural mechanics. }\end{array}$ \\
\hline$\star_{5}$. & $\begin{array}{l}\text { Web, smartphone, } \\
\text { tablet design }\end{array}$ & $\begin{array}{l}\text { Webpages, chatrooms, apps, electronic advertising, } \\
\text { and games. }\end{array}$ \\
\hline *6. & Film design & $\begin{array}{l}\text { Motion graphics, animation, motion } \\
\text { capture, augmented reality. }\end{array}$ \\
\hline
\end{tabular}

Source: Exploring the development of computer drawing in graphic design from a technology philosophy. ${ }^{\star}$ Note: The $5^{\text {th }}$ and $6^{\text {th }}$ points are personal additions. 


\section{Comparisons of Graphic Design Education Systems in Uganda, the Western World and China}

\subsection{Rural and City Locations}

In Uganda, secondary/high school and university students interested in learning graphic design live in the city and big towns, not the villages. This is because urbanised children are exposed to its elements through print media, by watching children's cartoons, animations and computer games at an early age.

In the West and China, city primary/elementary school children are exposed early to better quality and quantity of cartoons and animations than village children. This gives them a better understanding of design and technology by the time they start formal studies. Chinese city and some village primary schools also offer drawing and calligraphy lessons. These lessons help the students understand better and appreciate art and design when they encounter it later in life.

This is unheard of in rural Uganda. Basic primary education curricula are taught to students that are on average five lessons-mathematics, science, social studies, English and physical education. Furthermore, Western and Chinese students start formal art and design studies earlier than Ugandan students. While most Western and Chinese students attend drawing, calligraphy, painting and crafts lessons in primary and secondary school (4-17 years), the average Ugandan student starts formal art and crafts classes at in secondary school and university (13 - 22 years). By this time, a rural or urban Ugandan student has most likely made a decision to appreciate or reject art and design. Early-age design studies gives Western and Chinese students a five to nine year head-start at exploring and practicing their design skills and using design software ahead of Ugandan students.

\subsection{Gender Inequality}

There is a higher probability that more boys will study graphic design than girls in Uganda. While boys are encouraged to take risks in new fields of study, girls are cautioned to study the "safe" courses like medicine, engineering and law because they will marry and bare children.

Graphic design studies have been in Uganda since independence in 1962 but lay dormant until the late 1990s and early 2000s, where it peaked. Only in Kampala, the capital city, are there a handful of universities and institutions that formally teach graphic design. They include Makerere University, Nkumba University, Kyambogo University and Michelangelo College of Creative Arts (Mentioned Ugandan universities and school websites). Most of their students are male by gender.

\subsection{Historic Documentation}

The West and China have documents and records from their ancient civilizations to today that prove that commercial graphic design was taught and practiced, especially in China. It was first noticed in the Ming dynasty (1368-1644) 
through paintings and printing books. Later, French and American influences introduced graphics design to the Chinese cinema and television at the end of the $19^{\text {th }}$ century and beginning of the $20^{\text {th }}$ century. Such records and documents do not exist in Uganda. It may be as a result as the destruction of African civilisations and empires during the slave trade and colonisation eras whereby documents were destroyed and literacy was banned.

\subsection{Specialisation at Bachelors' Levels}

In Uganda, the university pedagogies are generalised. Most bachelors/undergraduate courses teach both Fine and Industrial/Commercial Art over a time span of three to four years. This means that a student is a fine art and design graduate upon finishing this course. For example, I graduated in painting and graphic design for my undergraduate/bachelor degree at Makerere University Kampala. In the West and China, the bachelors' studies are split up into fine arts, industrial design and art history. Furthermore, the industrial design courses in China are divided into sub fields like product design (Yang \& Sun, 2016; Luo 2011; Dziobczenski \& Person, 2018), landscape and environmental design, interior design, transportation design, fashion design (Wu \&Gao, 2011), fabric design, computer animation (Belmega, Lasaulce, \& Tembine Hamidou, 2010) and visual communication design, to mention a few.

Specialisation of these design courses can be applied in other support fields like software development (Yang \& Sun, 2016; Luo, 2011; Bodyan, Ponomarev, \& Melnichenko, 2017; Oscario \& Luzar, 2016; Wei, Zhang, \& Wei, 2009; Xue, Song, \& Li, 2017), electronics (Xue, Song, \& Li, 2011) and electrical studies, medical research (Wei, Zhang, Wei et al., 2009), mechanical design, robotics, fabric design, material science (Bodyan, Ponomarev, \& Melnichenko, 2017), film editing, factory automation, civil construction and geology (Wei, Zhang, \& Wei, 2009) and telecommunications (Chen, Owen, \& Wilson, 1972).

Several support courses are currently not taught in Ugandan universities. Furthermore, the old governments neither built industries for employment nor research centers for invention/innovation and therefore young employees are forced to learn these support fields on the job or travel abroad to learn about them. For example, some Ugandan architects tend to integrate architecture with interior design, mechanical engineers study ICT courses after graduation in order to fix software problems, I learnt basic pre-press engineering at my first print media company and photography at my second print media company where I worked as an information graphic designer.

These loopholes reduce the chances of Ugandan-taught graduates from seeking employment in graphic design companies or setting up graphics design industries in Uganda. Some prefer to work abroad or transition into other secure employment opportunities like advertising, transportation, trade and farming (Table 2).

\subsection{Computer Design Software Specified}

Most Western and Chinese universities specify the software programs that will 
Table 2. Graphic design pedagogies at bachelors' levels in uganda, the west and china).

\begin{tabular}{|c|c|c|c|}
\hline \multirow{2}{*}{ No. } & \multicolumn{3}{|c|}{ Comparisons } \\
\hline & Study Courses & Uganda & West and China \\
\hline 1 & Visual Communications $s_{1,2,10}$ & $\checkmark$ & $\checkmark$ \\
\hline 2 & Manufacturing Design $n_{1,2,3,10}$ & $\checkmark$ & $\checkmark$ \\
\hline 3 & Product Design $_{1,2,9,10}$ & $x$ & $\checkmark$ \\
\hline 4 & Fashion and Fabric Design $n_{1,2,4,10}$ & $\checkmark$ & $\checkmark$ \\
\hline 5 & Jewelry Design $_{1,4,10}$ & $\checkmark$ & $\checkmark$ \\
\hline 6 & Print and Publishing Design $n_{1,2,10}$ & $x$ & $\checkmark$ \\
\hline 7 & Font and Typography Design ${ }_{1,2,10}$ & $x$ & $\checkmark$ \\
\hline 8 & Web Design $_{1,2,10}$ & $x$ & $\checkmark$ \\
\hline 9 & Mobile Apps Design $_{1,2,5,6,10}$ & $x$ & $\checkmark$ \\
\hline 10 & Games Design $n_{1,2,5,6,10}$ & $x$ & $\checkmark$ \\
\hline 11 & Computer Animation $_{1,2,7,10}$ & $\checkmark$ & $\checkmark$ \\
\hline 12 & Film, TV Graphics ${ }_{1,2,8,10}$ & $\checkmark$ & $\checkmark$ \\
\hline 13 & Augmented Reality Design $_{1,10}$ & $x$ & $\checkmark$ \\
\hline 14 & Landscape, Environmental Design $n_{1,2,7,10}$ & $x$ & $\checkmark$ \\
\hline 15 & Interior Design $_{1,2,10}$ & $x$ & $\checkmark$ \\
\hline 16 & Engineering, Technical Design $n_{1,2,7,9,10}$ & $x$ & $\checkmark$ \\
\hline 17 & Medical, Health Design $n_{1,2,10}$ & $x$ & $\checkmark$ \\
\hline 18 & Robotics, AI Design $n_{1,2,10}$ & $x$ & $\checkmark$ \\
\hline
\end{tabular}

Sources: Exploring the development of computer drawing in graphic design from a technology philosophy, Computer graphic design software applications in graphic design, Applications and manufacturing; Computer-aided design and simulation of manufacturing processes in the packaging industry, Innovative study on material technology in jewelry exhibition design, Mobile games icons designs: A study based on graphic designer knowledge, Game theory and learning for wireless networks, Study on the engineering graphics system of 3D design software of arch dams, Automatic video annotation system for archival sports video, computer-aided design and graphics applied to the study of inductor-energy-storage DC-to-DC electronic power converters.

be taught during undergraduate studies. This is because the software packages have unique functions, advantages and some affiliated companies/employers utilise specific packages to make their products. Popular Computer Aided Design (CAD) software includes Adobe Creative Suite, CorelDraw Creative Suite, Autodesk packages, Rhino, 3D Max and Google Sketchup (Bodyan, Ponomarev, \& Melnichenko, 2017). Microsoft Office and Office 365 packages are not considered design software in China, which is the case in some Ugandan education institutions.

\subsection{Accessibility to Computers}

Many Ugandan students in primary and secondary schools have little to no access to computers. The available computers are either old or rundown because the good and new computers are used for commercial and administrative purposes. It is difficult to get a personal computer as a child because of the high 
birth rate of 7.2 children per woman. In this case, sharing of computers is the only option discouraging personal exploration and growth. Students get partial access at university and full access to good computers when they are employed or when they buy them. Most times, young employees share good computers because they are too expensive to purchase and maintain.

In the West and China, computers are affordable to buy and maintain. There is a home computer for a Chinese primary school child and s/he has uninterrupted access to this home computer because of the government one-child policy. In the West, women have an average of 1.6 children (Europe) to 3.1 children (North America). This means that each child also has a good chance to acquiring a personal computer when attending primary school.

\subsection{Internet/Wi-Fi Accessibility}

Internet and $\mathrm{Wi}-\mathrm{Fi}$ is considered a luxury in Uganda. Wi-Fi is used in major companies, affluent households, hotels and restaurants in Kampala. Upgrading and installing phone and computer software via Wi-Fi is done when opportunity presents itself. Affordable internet cafes in the villages still use dial-up systems making internet slow and tedious. The introduction of mobile data bundle USBs (dongles) helps ease internet communication within and when travelling out of Kampala, even though it is expensive.

Wi-Fi in China and the West is a necessity to daily life. People have fast and affordable Wi-Fi in their homes, schools, and companies. Students use Wi-Fi for daily activities like buying meals, transport, library access via their smart phones, making student life cheap and convenient.

Western and Chinese students are conversant with online libraries and design communities by the time they study their bachelors/undergraduate studies because of free or cheap Wi-Fi. Ugandan bachelors' students, on the other hand, must pay huge fees to "surf" the floods of online information when using the internet and Wi-Fi.

There are free and cheap Wi-Fi zones at major Western and Chinese airports and train stations as well as inside trains and airplanes. These cheap/free zones make travelling while studying/working easy. Entebbe International Airport in Uganda has free Wi-Fi in selected zones and major bus stations do not offer Wi-Fi services. One can only depend on mobile data.

\subsection{Invention and Innovation}

Young, curious minds invent new products/services and innovate ways to improve the existing ones. They need two factors to turn their new ideas into reality-experimentation and application. This means that laboratories and experimental market grounds are established and thriving. This has been the case in the West for centuries.

China is still known as the "copycat" or implementer of these groundbreaking inventions and innovations on large scale industrial levels. The Chinese gov- 
ernment is gradually encouraging inventions and innovations to replace mass duplication of existing products in their current industrial campaign of transforming "Made in China" to "Made by China".

The Ugandan government is way behind the "Made in Uganda" and "Made by Uganda" policies. Uganda is still an agro-based country with little large-scale industrialisation and backdated technology. Uganda imports more industrial design products than it produces, exiling local inventors and innovators to migrate to the diaspora (other countries) that provide facilitation.

\subsection{Internship/Work Mentorship}

Internship is a necessary transition from student to employee status. It is encouraged in the West, China and Uganda. Nowadays, education institutions and affiliate companies partner to train promising students into productive professional designers (Dziobczenski \& Person, 2018; Luo, 2011; Yang \& Sun, 2016; Wei, Zhang, \& Wei, 2009). Most Western and Chinese technological universities take step further to conduct exchange program internships with local and international affiliates, creating self-sustaining environments and improving interpersonal and international relationships.

\subsection{Seminars/Workshops and Competitions}

Western and Chinese technological universities hold competitions and workshops per semester. These workshops may be internal (a lecturer conducts with his students) or external whereby they invite a professor/professional from other universities/companies. These competitions and workshops encourage students to think as company employees who in turn understand "companies demands" instead of studying to pass examinations (Dziobczenski \& Person, 2018).

In Uganda, most students attend workshops and competitions after employment. This means that they are disadvantaged even at job interviews. They draft poor resumes, they dress and behave inappropriately in interviews and they have mismatched or zero portfolios. These disadvantages cause them to unemployed, underemployed causing job insecurity or early termination.

\section{Indirect Factors Affecting Chinese and Ugandan Education Systems}

\subsection{Language Preservation and Promotion}

Chinese students take fine art and graphic design studies in Mandarin (汉语) from primary to university level. This language preserves their long history and culture. It also adjusts to modern demands, keeping it relevant today. Chinese characters are computerised into both traditional and simplified characters hence preserving and promoting its value. Ancient calligraphy and ink painting have been given a modern look and purpose in 2D and 3D print and film designs.

Uganda has one local national language-Luganda. Most rural students in Central Uganda learn their primary lessons in Luganda. The rural children in 
the rest of the country learn in their mother tongues while the city primary children are strictly taught in English. English is formerly used in all secondary studies while Luganda takes a backseat as an elective subject. This means that Luganda is formally taught to a limited number of people for a limited time. These conditions cause stagnation of the language since it is not formerly taught to all Ugandan students at primary, secondary and university levels. The Luganda language and culture is behind in terms of higher education terminologies and modern technology and is forced to use borrow words from English, rendering it static.

Upon searching mobile apps, I realised that Luganda is currently used in English-Luganda translation dictionaries and religious apps like the holy bible and the holy Quran. There are no Luganda apps promoting literature, music and technology. These factors mean that the preservation and promotion of traditional culture and folklore is greatly diminished.

\subsection{Chinese Culture Modernises While Preserving Values but Some of Uganda's Culture Is Dying Because of Modernisation}

Chinese people, like Europeans, are maestros at documentation-historic and modern. Their history and culture date back to ancient civilizations as far back as the Xia dynasty (2070-1600BC). Information from this dynasty was documented and preserved in bamboo annals. In Uganda, ancient tribal traditions can only be dated back a few centuries because of little documentation. Most information was passed on orally causing the loss of vital information.

Slavery and colonisation "left a hole" in Uganda and Africa's ancient culture. Africa's military weakness allowed Arab and European slave traders to destroy old civilisations as they pillaged kingdoms looking for young, strong slaves over a period of four $\left(15^{\text {th }}\right.$ to $\left.19^{\text {th }}\right)$ centuries. They left behind infants, the elderly and sick to who could not sustain themselves let alone rebuild the destroyed kingdoms. Slaves were prohibited from reading and writing so as to prevent the documentation of their cultures and their slave experiences.

European governments/monarchies quickly replaced abolition of slavery with colonialism and neo-colonialism for another four $\left(19^{\text {th }}\right.$ to $\left.21^{\text {st }}\right)$ centuries. The British Empire switched from enslaving people to pillaging Uganda and Africa's resources by through oppressive colonial systems. European colonial governments banned the use of local literature, technology and artisanship to promote their products and ideologies, leading to a huge loss of African culture and information. These negative effects are felt today amongst Africans and stolen African descents living in the Americas and the Middle East (Nunn, 2018; Whatley \& Gillezeau, 2011; Moyo, 2009; Moyo, 2012; Albiman 2016).

Chinese military strength ensured the preservation of its traditions and culture. Even though eight countries-six of them from Europe (Britain, France, Germany, Russia, Italy, Austria, United States and Japan) invaded China, the Chinese people were able to fend off the annihilation of their cultures and technology. Secondly, the time periods of occupation in China (5 to 99 years) were 
shorter than Uganda and Africa (about 6 centuries). Whatever traditions and culture their colonial masters destroyed, they recovered and rebuilt them.

Artistic skills, craft making and technological secrets were passed down from one generation to the next with detailed instructions and training before being shared. Some of these skills were kept secret amongst their communities, for example, military engineering and tactics, architecture and cuisines. Today, these skills are identified as uniquely Chinese intellectual properties. In Uganda, most traditional skills were practiced and preserved orally after the $15^{\text {th }}$ century causing cultures and technology to disappear or blend into other cultures. For example, traditional languages and songs are still unique but traditional fashions and cuisines have been blended by Persian and Asian influences.

\section{Suggestions to Improve the Current Ugandan Education Systems}

These suggestions are proposals and discussions from the author that should assist in bridging the graphic design studies gap between Uganda and the West and China.

\subsection{Parents and Guardians}

Parents and guardians in Uganda are the first people to recognise their children's talents and gifts at an early age. They should take a leaf from Western and Chinese parents and actively encourage their children to discover these talents. Ugandan parents should also learn to protect and patent their children's inventions and innovations, no matter how young the child is. By doing this, they prevent loss of intellectual property, child abuse and promote ingenuity, early employment and entrepreneurship. These positive actions will make budding designers productive individuals who will have good job security, pay taxes and investors in their new fields.

The rural Ugandan woman should use child spacing and birth control so as to reduce the current average number of 7.2 to 2 - 3 children. Reduction in the high birth rate will prevent high household debt making purchasing and maintenance of a home computer possible.

\subsection{Education Institutions}

About $80 \%$ of Ugandan population is young ( $1-25$ years) whereby most of them are rural children. Rural primary schools should utilise the available local resources to teach primary school children art and crafts so that the lessons are affordable and self-sustaining. Natural resources like banana trees, papyrus reeds, bamboo trees and soft wood can be grown in and around the schools throughout the year. The education system needs to phase out and eventually divorce itself from using imported materials and encourage local material usage for self-sustenance and development.

Gender discrimination should be discouraged from fine art lessons and 
graphic design lessons in primary, secondary schools and at university. Talent and hard work should be the defining parameters, not whether a person is a woman or man.

Fine art lessons and design studies should be taught in rural districts in Uganda, not only in the capital city. This will encourage increase in the quantity and quality of art and design students. This will in turn increase development of local artisan skills and local materials especially in product design technology, material design and environmental design sectors.

Current rural primary and secondary education schools need computers as an integral part of teaching and learning. Blackboard education in the West and China has been modernised with projection presentations, video and sound. The computers should have appropriate computer software installed and Wi-Fi services enabled that are powered by regular electricity supplies. Biogas and solar electricity are great supplements/alternatives to the unreliable national hydro-electricity currently distributed. All these changes are capital intensive so the Ugandan education ministry needs to plan to support these rural schools in terms of investment.

\subsection{Government}

Specialisation thrives when all interrelated systems are functional and aware of their roles in the "factory line" production. If one element is unavailable, weak or mismatched, it will stop the workflow. The education ministry should carefully plan and manage these different courses with the relevant education institutions. Specialisation encourages economic development because multiple education systems, companies and industries are created instead of one company. Uganda needs to shift from producing unprocessed and semi-processed products to a fully processed product. This way, there is full control of its inception, research, planning, education and manufacturing (Moyo, 2009; Moyo, 2012; Albiman, 2016).

Inventions are made by rigorous repetition, adjustments and introduction of new elements or by sheer chance. If lucky chances occur, research is still conducted to ascertain how it came about. For invention and innovation to be appreciated, research has to be done, products need to be tested, laws need to be enforced, capital investment for large-scale production of these new and improved products, marketing and advertising needs to be sunk. These processes need governmental approval and protection to thrive.

The ministry of education can take a leaf from the West and China whereby capital investment has been made in future design ideas and breakthroughs. If Uganda fails to catch up with modern inventions and innovation, she will continue to be a debt-ridden country because she will continue to import more goods than manufacture and export.

The Luganda language should be taught to all students from primary to university levels. This way, students are given chances to maintain and modernise it. 
The Nilotic regions' rejection of Luganda hampers its sustenance and growth. They need to reconsider the future of Luganda and understand that by preserving this language, they will also preserve their own languages. Luganda needs to modernise quickly and smartly. Language and culture experts need to upgrade their teaching techniques from print to electronic/mobile phone materials. This way, they can attract the youth using modern methods (Mutekwe, 2015; Vuyisile, 2013).

Uganda cannot reverse the damages of slavery and colonisation. It needs to use the experiences from this painful past to restart and rebuild. For example, African Americans use the slave traders and owners' records to recover and retrace their roots and cultures (Nunn, 2018; Whatley \& Gillezeau, 2011). Kenya recently used documents and recordings from British Colonial Archives to learn more about their cultural origins. The voice recordings of Maasai chiefs' meetings with the British East Africa Trading Company of the late 1800s were returned to the Maasai leaders in 2014 to analyse the language and phonetics. Ugandan authorities need to recover whatever cultural relics were kept in the British colonial archives e.g. 1900 Buganda Agreement, the court trials of kings Kabalega and Mwanga.

Relevant cultural and government authorities need to set up institutions that will document forty-plus local languages, culture, art and technical skills. For example, the materials used for making local drums like the Buganda bakisimba and Runyoro runyege should be documented and skills passed on to future generations. Oral communication should be replaced with recordings and written documentation so that regular changes are archived. This way, future generations will better understand the development of their languages and culture (Nunn, 2018; Whatley \& Gillezeau, 2011; Figure 1).

\section{Conclusion}

Western and China's graphic design education systems have successfully modernised and partnered with local and international commercial, industrial and engineering sectors to produce students who are well prepared for employment, job security and investment.

Western and Chinese dynasties and governments have created political stability and security for long time periods hence creating positive conditions for investment and advancement its education policies from ancient people and current populations. This ensures that students can confidently invest in inventions and innovations for employment and better job security. Uganda's political instability from slavery until the current 1986 government caused destruction of civilisations, education, commerce and industrialisation. These conditions have caused the stagnation of artistic and technological development and increased "brain-drain" (migration of labor from Uganda to other countries). This is because these countries offer better employment opportunities and job security.

Uganda's heavy debts from foreign aid halts the capital investment needed to 


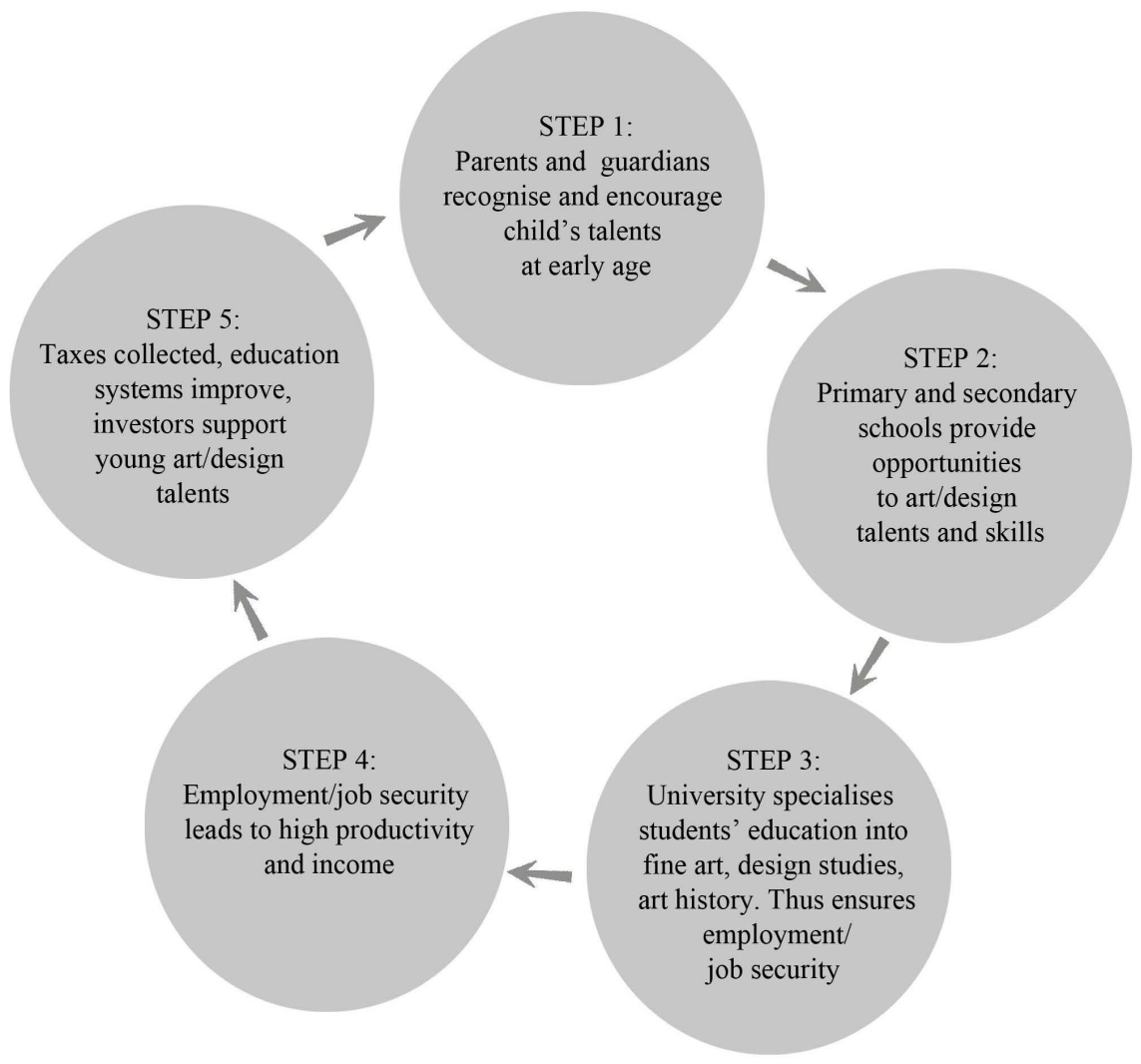

Figure 1. Chart cycle illustrating self-sustainable design education systems for Uganda. Sources: Exploring the development of computer drawing in graphic design from a technology philosophy, Computer graphic design software applications in graphic design, Applications and manufacturing; computer-aided design and simulation of manufacturing processes in the packaging industry, Innovative study on material technology in jewelry exhibition design, Mobile games icons designs: a study based on graphic designer knowledge, Learning to precode in outage minimization games over MIMO interface channels, Study on the engineering graphics system of 3D design software of arch dams, Automatic video annotation system for archival sports video, Computer-aided design and graphics applied to the study of inductor-energy-storage DC-to-DC electronic power converters, Graphic designer wanted: a document analysis of the described skill set of graphic designers in job advertisements from the United Kingdom, Mentioned Ugandan universities and schools websites.

modernise its education institutions from primary to university levels. The finance ministry needs to find comprehensive ways to end these "debt pits" and create investment opportunities for modern education. China owes no debt to any country and the West is self-sustaining and/or skillfully manages its debt despite the 2008 financial crisis. They both modernise their education systems regularly and invest in other countries' development.

The Ugandan education ministry should continue to partner with positive Western and China projects that assist to improve its current systems so that it can achieve its goal of remaining East Africa's education centre.

Last but not least, Ugandan parents and guardians have the most important role of identifying their child's talents and skills at an early age. They need to 
learn that they have the responsibility of developing and protecting these talents like their Western and Eastern counterparts and should take an active role in doing so.

\section{Acknowledgements}

Salutations go to my study supervisors, Professors Fang Xing and Lv Jiefeng for their guidance through this publication process. Salutations also go to my Proverbs 31 aunts who opened doors for my $\mathrm{PhD}$ education.

\section{Conflicts of Interest}

The author declares no conflicts of interest regarding the publication of this paper.

\section{References}

Albiman, M. M. (2016). What Are the Impact of Foreign Aid to the Economic Growth? Time Series Analysis with New Evidence from Tanzania. Business and Economics Journal, 7, 237.

Belmega, E. V., Lasaulce, S., \& Tembine, H. (2010). Learning to Precode in Outage Minimization Games over MIMO Interface Channels. Conference Record of the Forty Four Alisomar Conference on Signals, Systems and Computers, Pacific Grove, CA, 7-10 November 2010. https://ieeexplore.ieee.org/document/5757513

Bodyan, L. A., Ponomarev, A. P., \& Melnichenko, M. A. (2017). Computer-Aided Design and Simulation of Manufacturing Processes in the Packaging Industry. International Conference on Industrial Engineering, Applications and Manufacturing, St. Petersburg, 16-19 May 2017.

Chen, D. Y., Owen, H. A., \& Wilson, T. G. (1973). Computer-Aided Design and Graphics Applied to the Study of Inductor-Energy-Storage DC-to-DC Electronic Power Converters. IEEE Power Processing and Electronics Specialists, AES-9, 585-597.

Dziobczenski, P. R. N., \& Person, O. (2018). Graphic Designer Wanted: A Document Analysis of the Described Skill Set of Graphic Designers in Job Advertisements from the United Kingdom. International Journal of Design, 11, 41-55.

Luo, D. (2011). Computer Graphic Design Software Applications in Graphic Design. Proceedings of 2011 IEEE International Conference on Electronic \& Mechanical Engineering and Information Technology, Harbin, 12-14 August 2011.

https://ieeexplore.ieee.org/document/6023663

Mentioned Ugandan Universities and Schools Websites: http://cedat.mak.ac.ug/ https://courses.mak.ac.ug/programmes/bachelor-industrial-and-fine-arts https://nkumbauniversity.ac.ug https://ugfacts.net/list-courses-offered-kyambogo-university-kyu/ http://www.schoolsuganda.com/michelangelo-college-of-creative-arts

Moyo, D. (2009) Dead Aid: Why Aid Makes Things Worse and There Is Another Way for Africa. London: Penguin, Google Books.

Moyo, D. (2012). Winner Take All: China's Race for the World's Resources. New York: Basic Books, Google Books.

Mutekwe, E. (2015) Towards an African Philosophy of Education for Indigenous Knowledge Systems in Africa. Creative Education, 6, 1294-1305. 
https://doi.org/10.4236/ce.2015.612129

Nunn, N. (2018). The Long-Term Effects of Africa's Slave Trades. Quarterly Journal of Economics, 123, 139-176. https://doi.org/10.1162/qjec.2008.123.1.139

Oscario, A., \& Luzar, L. C. (2016). Review of Mobile Games Icons Designs: A Study Based on Graphic Designer Knowledge. 1st International Conference on Game, Game Art, and Gamification (ICGGAG), Jakarta, 19-21 December 2016.

Vuyisile, M. (2013). Stephen Biko's Philosophy and Its Pedagogical Implications in South Africa. Creative Education, 4, 492-496. https://doi.org/10.4236/ce.2013.48071

Wei, Q., Zhang, G. X., Wei, J. Y. et al. (2009). Study on the Engineering Graphics System of 3D Design Software of Arch Dams. IEEE Youth Conference on Information, Computing and Telecommunication, Beijing, 20-21 September 2009.

Whatley, W., \& Gillezeau, R. (2011). The Fundamental Impact of the Slave Trade on African Economies. Economic Evolution and Revolution in Historical Time, 86-110. https://doi.org/10.11126/stanford/9780804771856.003.0004

Wu, G.-R., \& Gao, C.-M. (2011). Innovative Study on Material Technology in Jewelry Exhibition Design. IEEE 18th International Conference on Industrial Engineering and Engineering Management, Changchun, 3-5 September 2011, 1375-1377. https://ieeexplore.ieee.org/document/6035411

Xue, Y. Y., Song, Y. L., Li, C. E. et al. (2017). Automatic Video Annotation System for Archival Sports Video. IEEE Winter Applications of Computer Vision Workshops (WACVW), Santa Rosa, CA, 24-31 March 2017.

https://ieeexplore.ieee.org/document/7912204

Yang, C.-F., \& Sun, C.-S. (2016). Exploring the Development of Computer Drawing in Graphic Design from a Technology Philosophy. IEEE Symposium on Service-Oriented System Engineering (SOSE), Oxford, 29 March-2 April 2016.

https://ieeexplore.ieee.org/document/7473045 